\title{
Increasing the evidence base on the role of the community in response to HIV/AIDS
}

\author{
Rosalía Rodriguez-García, René Bonnel
}

\begin{abstract}
'Effectiveness' became a rallying cry for the international development community a decade ago, as governments and major aid donors recognised that spending more money on health and other projects in developing countries was not always achieving the desired results. Donors and host countries began to coordinate their efforts and to 'manage for results', meaning that they placed increased emphasis on the tangible results of aid in people's lives, and sought better ways to measure those results (World Bank, 2006). ${ }^{1}$
\end{abstract}

In the HIV and AIDS field, communitybased organisations (CBOs) were at the forefront of the global response to the epidemic from the beginning and organised themselves to care for those in need (UNAIDS, 2006). ${ }^{2}$ CBOs working on HIV and AIDS now form a rich and complex web of organisations around the world, working along the entire continuum of prevention, care, treatment and support (Rodriguez-García et al, 2011). ${ }^{3}$ Although CBOs have been receiving increased financial support from major aid donors, especially since 2000, their effectiveness was not initially documented in a systematic and rigorous way. The sheer variety of $\mathrm{CBO}$ and the broad nature of their work have been the barrier to a structured evaluation of their impact.

This special supplement to the Journal of Epidemiology and Community Health presents a range of approaches to monitoring and assessing the role of community mobilisation and structural interventions in HIV prevention, using the example of Avahan, the India AIDS Initiative of the Bill and Melinda Gates Foundation. Social scientists, epidemiologists, practitioners, community organisers and activists have approached the

Human Development Network, The World Bank, Washington, DC, USA

Correspondence to Dr Rosalía Rodriguez-García, Human Development Network, The World Bank, $1818 \mathrm{H}$ street NW, Washington, DC 20433, USA;

rrodriguezgarcia@worldbank.org programme from different standpoints to learn from its implementation. The efforts presented here demonstrate that there is considerable merit in collecting data on high-risk group communities to inform policy-making and improve management, and for the use of the communities themselves.

The papers in this supplement add to the evidence base on the role of communities and CBOs in HIV and AIDS response. In this they complement efforts such as those of the World Bank, which has joined the UK Department for International Development (DFID) in a similar endeavour to measure the effects of $\mathrm{CBO}$ activities in response to HIV and AIDS. A multi-method system of evaluation was devised through consultations with the UK Consortium on AIDS and International Development as well as technical experts at the global and country level. Civil society organisations were explicitly and actively encouraged to provide input and advice throughout the process of design and implementation. The evaluation took the form of 11 studies of several types, gathering both quantitative and qualitative data, and was implemented from 2009 to 2011 in eight countries (Burkina Faso, India, Kenya, Nigeria, Lesotho, Senegal, South Africa and Zimbabwe). ${ }^{4}$ The analytical synthesis and studies that formed this evaluation will be published in 2012 in a special issue of the Journal AIDS Care.

The underlying premise of evaluations of community groups, such as those supported by the World Bank and DFID, as well as those presented in this supplement is that the behaviours and conditions that promote HIV transmission, as well as individual capacity to access prevention and other services, are influenced by social norms and values of communities. There is an assumption that meaningful participation by high-risk group members in HIV interventions, structural interventions and organisational developmental activities leads to identification, collectivisation and owner- ship, which in turn leads to improved programme outcomes. These assumptions must be explored and justified if they are to be effective policy arguments.

The papers in this supplement address these issues and raise important questions for those seeking to learn from operational approaches, and to undertake the often complex data collection and analysis required to understand how change occurs in programmes. How is the organisational strength of community groups defined and measured? What are the methodological approaches that can be used to evaluate the response to the epidemic by groups that exist across a variety of social and geographic contexts?

Those are some of the questions that the papers in this supplement attempt to answer by triangulating data from routine monitoring systems, behavioural and organisational monitoring surveys, crosssectional surveys collecting both biological and behavioural data, and key informant interviews.

The findings in this supplement make important and timely arguments for the effectiveness of HIV and AIDS responses, and are likely to be used more widely over the coming year. UNAIDS and major donors including the Global Fund to Fight AIDS, Tuberculosis and Malaria and PEPFAR (the US government's AIDS programme) are emphasising the importance of community systems and services in their current strategies, investment approaches or programmes. Taken in isolation, the studies in this supplement provide only partial information on one or a few aspects of how communities respond to HIV and AIDS. However, taken together, these analyses provide a body of evidence that helps to corroborate effects that are common to the community response in varying contexts.

The evidence for the effectiveness of community mobilisation, structural interventions and community-based groups comes at a time when financial resources for HIV and AIDS have been flat-lined at the global level, and donors and governments alike are being forced to do more with less. Although it remains a challenge to prove that these approaches are the best investment for all HIV and AIDS monies, the results in this supplement and the soon-to-be-published work by the World Bank and DFID show that these approaches are a good investment. Above all, the findings argue in favour of continued engagement with those working around the world on the frontlines of community response to this epidemic. 
Acknowledgements The authors wish to thank Gina Dallabetta and Tisha Wheeler from the Gates Foundation, and Isabelle de Zoysa for valuable comments on an early draft of this commentary.

Commissioned commentary for the forthcoming special supplement of the journal on the community mobilisation features of the Avahan India AIDS Initiative guest edited by Isabelle de Zoysa.

Contributors $R R-G$ and $R B$ are the only contributors to this paper.

Competing interests The opinions expressed in this paper are those of the authors only and need not represent the views of the World Bank, its Executive Directors or the countries they represent.
Provenance and peer review Commissioned; internally peer reviewed.

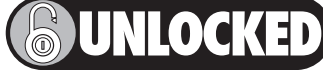

This paper is freely available online under the BMJ Journals unlocked scheme, see http://jech.bmj.com/site/ about/unlocked.xhtml

J Epidemiol Community Health 2012;66:ii7-ii8. doi:10.1136/jech-2012-201298

\section{REFERENCES}

1. World Bank. Managing for Development Results Principles in Action: Sourcebook on Emerging
Good Practice. 1st edn. World Bank, 2006. http:/www. mfdr.org

2. UNAIDS. The essential role of civil society. Report on the Global AIDS Epidemic. A UNAIDS $10^{\text {th }}$ Anniversary Special Edition. Geneva: UNAIDS, 2006:202-22.

3. Rodriguez-García R, Bonnel R, Njie N, et al. Analyzing Community Responses to HIV and AIDS: Operational Framework and Typology. Washington, DC: World Bank, 2011. Policy Research Working Paper \#5532.

4. Investing in Communities to Achieve Results: Findings from the Evaluation of the Community Response to HIV and AIDS. http://aidsconsortium.org.uk/day-1-ofinvesting-in-communities-to-achieve-resultsfindingsfrom-the-evaluation-of-the-community-response-to-hivand-aids/ 